\title{
BMJ Open Identifying priorities for primary care investment in Ireland through a population-based analysis of avoidable hospital admissions for ambulatory care sensitive conditions (ACSC)
}

Geraldine McDarby, Breda Smyth

To cite: McDarby G, Smyth B. Identifying priorities for primary care investment in Ireland through a populationbased analysis of avoidable hospital admissions for ambulatory care sensitive conditions (ACSC). BMJ Open 2019;9:e028744. doi:10.1136/ bmjopen-2018-028744

- Prepublication history and additional material for this paper are available online. To view these files, please visit the journal online (http://dx.doi org/10.1136/bmjopen-2018028744).

Received 27 December 2018 Revised 07 October 2019 Accepted 09 October 2019

Check for updates

(C) Author(s) (or their employer(s)) 2019. Re-use permitted under CC BY-NC. No commercial re-use. See rights and permissions. Published by BMJ.

Planning for Health Group, Department of Public Health, HSE West, Health Services Executive, Galway, Ireland

Correspondence to Dr Geraldine McDarby; germcdarby99@gmail.com

\section{ABSTRACT}

Background In 2016, the Irish acute hospital system operated well above internationally recommended occupancy targets. Investment in primary care can prevent hospital admissions of ambulatory care sensitive conditions (ACSCs).

Objective To measure the impact of ACSCs on acute hospital capacity in the Irish public system and identify specific care areas for enhanced primary care provision. Design National Hospital In-patient Enquiry System data were used to calculate 2011-2016 standardised bed day rates for selected ACSC conditions. A prioritisation exercise was undertaken to identify the most significant contributors to bed days within our hospital system. Poisson regression was used to determine change over time using incidence rate ratios (IRR).

Results In 2016 ACSCs accounted for almost $20 \%$ of acute public hospital beds ( $\mathrm{n}=871328$ bed days) with adults over 65 representing $69.1 \%$ ( $n=602392)$ of these. Vaccine preventable conditions represented $39.1 \%$ of ACSCs. Influenza and pneumonia were responsible for $99.8 \%$ of these, increasing by $8.2 \%$ (IRR: $1.02 ; 95 \% \mathrm{Cl} 1.02$ to 1.03 ) from 2011 to 2016 . Pyelonephritis represented $47.6 \%$ of acute ACSC bed days, increasing by $46.5 \%$ (IRR: 1.07 ; $95 \% \mathrm{Cl} 1.06$ to 1.08 ) over the 5 years examined. Conclusions Prioritisation for targeted investment in integrated care programmes is enabled through analysis of ACSC's in terms of acute hospital bed days. This analysis demonstrates that primary care investment in integrated care programmes for respiratory ACSC's from prevention to rehabilitation at scale could assist with bed capacity in acute hospitals in Ireland. In adults 65 years and over, including chronic obstructive pulmonary disease patients, the current analysis supports targeting community based pulmonary rehabilitation including pneumococcal and influenza vaccination programmes in order to reduce the burden of infection and hospitalisations. Further exploration of pyelonephritis is necessary in order to ascertain patient profile and appropriateness of admissions.

\section{INTRODUCTION}

Ambulatory care sensitive conditions (ACSCs) are acute or episodic conditions where appropriate and timely community care can
Strengths and limitations of this study

- The study examines the impact of ambulatory care sensitive conditions (ACSCs) on the acute publicly funded hospital system using national level data extracted from the national Hospital In-patient Enquiry System in the form of bed days and bed day rates.

- National bed day rates are standardised to the European Union population with three age-specific cohorts analysed (children 0-15, adults 15-64 and persons 65 and older) as well as trend analysis over the 5-year period 2011-2016 using Poisson regression techniques.

- All 19 ACSCs identified are included in the prioritisation exercise which identifies the top five contributors to ACSC bed days for the total population as well as for each age cohort examined.

- While the current analysis of capacity and age cohorts remains robust, further in-depth analysis of patient profiles was limited by the episodic nature of Irish National Hospital In-patient Enquiry System data, where admissions are not linked to patient details.

- The generalisability of all ACSC research is limited by poorly defined categorisation of ACSCs internationally, and a refinement of coding would enhance specificity and generalisability of this area of research.

prevent disease and/or hospital admissions. ${ }^{1}$ While there is variability in relation to the conditions considered ACSCs, they can be broadly classified into vaccine preventable, acute and chronic conditions. ACSCs are commonly used as an indicator of avoidable hospital admissions as well as quality of and access to primary care. ${ }^{23}$

The current Irish acute hospital bed occupancy rate of $94.2 \%$ is significantly higher than the internationally recognised target of $85 \%$. Occupancy rates at this level are associated with adverse patient and staff outcomes 


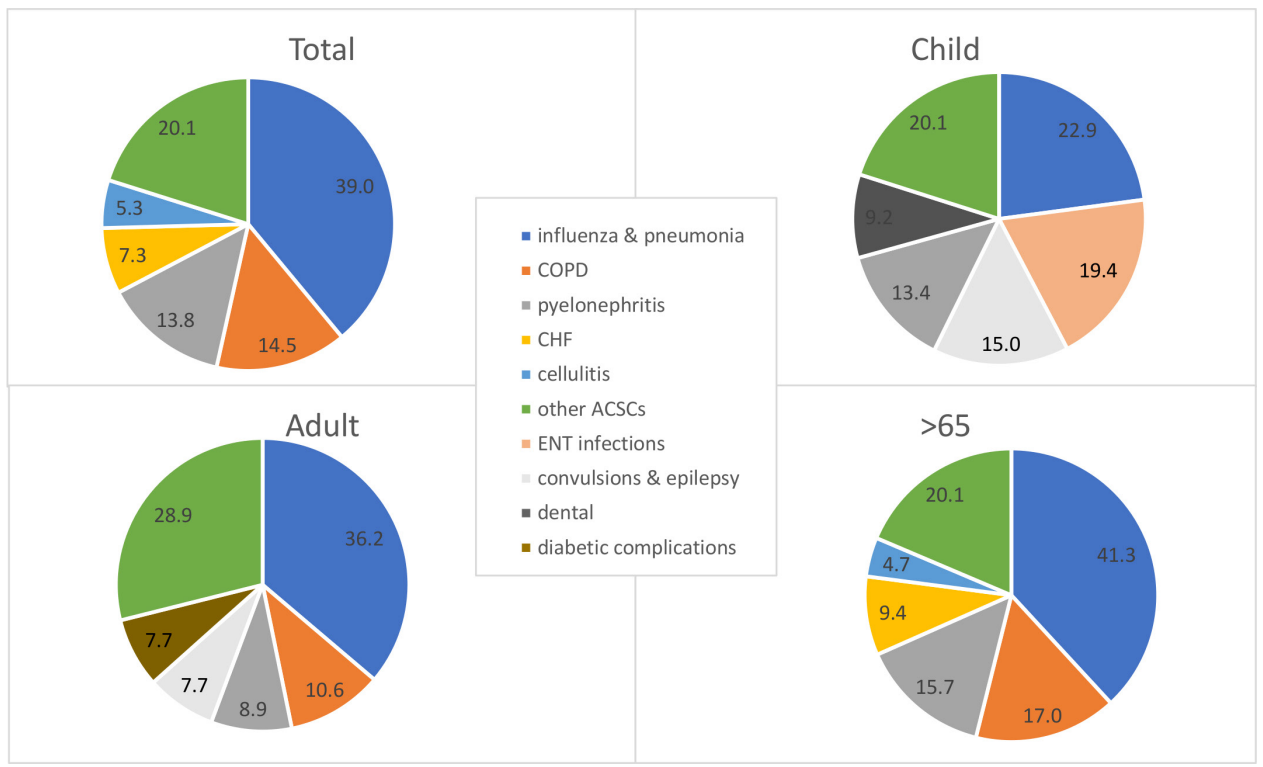

Figure 1 Impact of ACSCs on bed days in public acute hospitals in Ireland in 2016 by age cohort. ACSC, ambulatory care sensitive condition; COPD, chronic obstructive pulmonary disease.

as well as restricting efficiency in terms of patient flow. ${ }^{4}$ To achieve international standards of bed occupancy would require the immediate introduction of 1260 inpatient beds. ${ }^{5}$ Ireland is experiencing an ageing demographic shift with an expected annual increase of almost 20000 in the population 65 years and over. This population cohort currently occupy $54 \%$ of total acute bed days. ${ }^{6}$ Moreover, the demand for acute hospital beds is projected to increase significantly unless there is a shift in the model of care from acute hospital care to primary care. ${ }^{6}$ The hospital centric nature of the Irish system continues to fuel an ever increasing demand for acute hospitals to deliver care and services which would be better provided in the community. However, primary care services in Ireland remain under resourced. ${ }^{7}$ As recognised within Slaintecare, the 10 -year cross political vision for the future of Irish healthcare services, improvement and sustainability of the Irish Health system is dependent on a shift of care from acute hospitals to primary care. ${ }^{7}$

In the literature, ACSC analyses to date recognises the impact on emergency departments and admissions. Drivers of these admissions have been examined highlighting the association with levels of primary care provision, as well as higher levels of deprivation. ${ }^{18-10}$ However, the use of ACSC analysis to identify and prioritise areas for improved primary care resources and programmes of care remains unexamined. The purpose of this paper is to examine ACSCs in relation to their overall impact on acute hospital capacity in Ireland in terms of bed days and bed day rates and to assist prioritisation of targeted investment in primary care supporting robust integrated care programmes. This novel approach to the evaluation of ACSCs supports the left shift to primary care called for by Slaintecare and international policy.

\section{METHODS}

The international literature in relation to 'definition and coding' of ACSCs was reviewed and a list of 19 commonly cited ACSCs was identified for inclusion (online supplementary appendix 1). Definition notes for International Classification of Disease (ICD) codes including primary and secondary diagnoses were examined and the definition notes most appropriate to the Irish setting and reflective of bed utilisation were chosen. Data for these codes was extracted from the National Hospital In-patient Enquiry System to calculate 2011-2016 age-standardised bed day rates for selected ACSC conditions. Age specific analysis was carried out using the following categories; children (0-14 years), adults (15-64 years) and persons 65 years and over. A prioritisation exercise in which all 19 conditions were ranked in terms of their contribution to total and age specific bed days and bed day rates in 2017 was undertaken to identify the most significant contributors within our hospital system (figure 1). Poisson regression analysis was used to distinguish a genuine change over time. Standardised incidence rate ratios (IRR) with $95 \%$ CIs and corresponding $\mathrm{p}$ values were reported. ${ }^{10}$ Population rates are directly standardised to the European standard population.

\section{Patient and public involvement}

Patients were not involved in the concept or design of this study.

\section{RESULTS}

ACSCs represented $18.5 \% \quad(\mathrm{n}=871328)$ of publicly funded bed days in Ireland in 2016 with an $18.2 \%$ (IRR 1.03 ; $\mathrm{p}<0.01$ ) increase over the 5 -year time period examined. The most significant contributors to ACSC bed days included influenza and pneumonia, chronic obstructive 


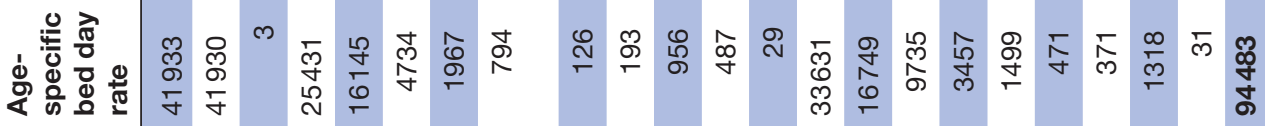

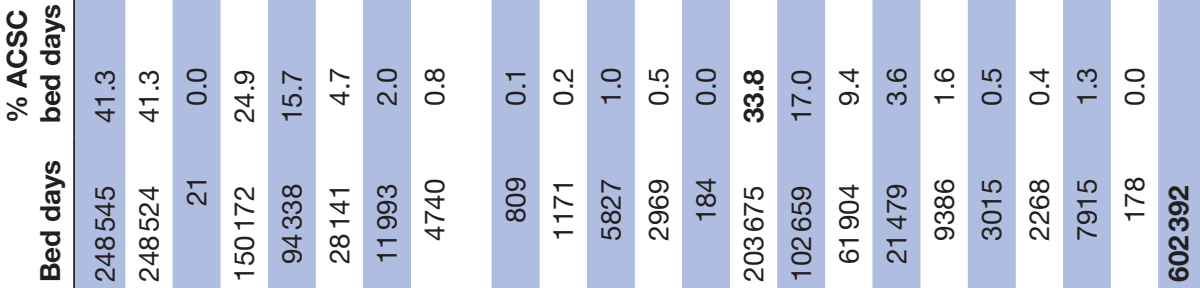

응

《i S त्र

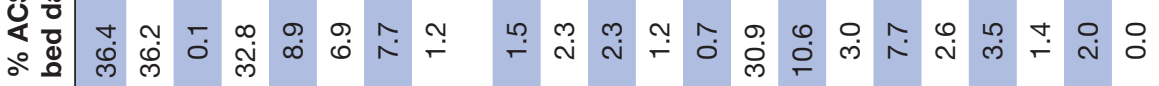

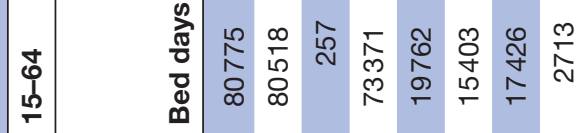

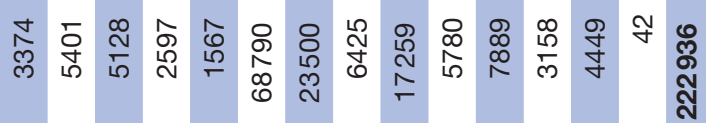

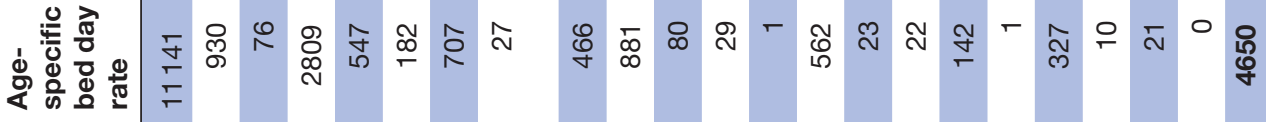

他

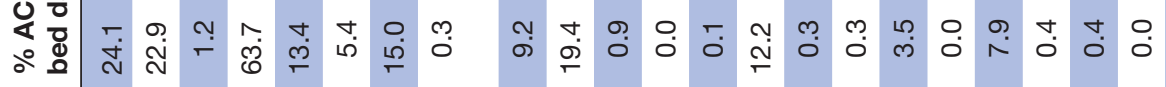

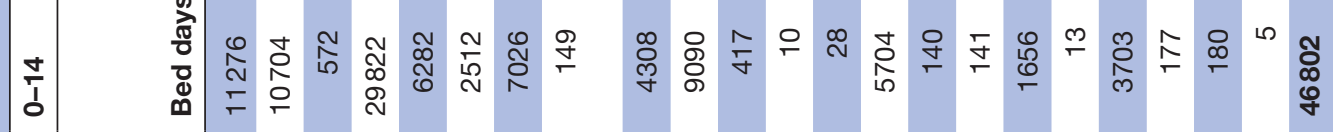

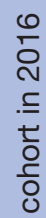

要

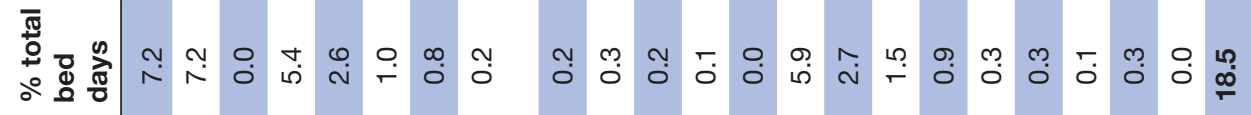

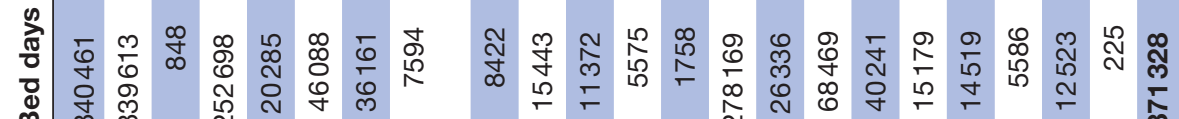


Table 2 Trend analysis of ACSC bed days in Irish acute public hospitals 2011-2016

\begin{tabular}{|c|c|c|c|c|}
\hline ACSC & $\begin{array}{l}\text { Absolute change } \\
\text { in bed days }\end{array}$ & $\begin{array}{l}\% \text { change in } \\
\text { standardised bed day } \\
\text { rate }\end{array}$ & $\begin{array}{l}\text { Incidence rate ratio for } \\
\text { trend }\end{array}$ & $95 \% \mathrm{Cl}$ \\
\hline \multicolumn{5}{|l|}{ Vaccine preventable } \\
\hline Total & 62395 & 8.2 & $1.02^{\star \star *}$ & 1.017 to 1.027 \\
\hline Influenza and pneumonia & 62700 & 8.2 & $1.02^{\star \star \star}$ & 1.018 to 1.027 \\
\hline Other vaccine preventable & -305 & -25.4 & $0.90^{*}$ & 0.791 to 1.014 \\
\hline \multicolumn{5}{|l|}{ Acute } \\
\hline Total & 56773 & 19.7 & $1.03^{\star \star \star}$ & 1.028 to 1.040 \\
\hline Pyelonephritis & 46554 & 46.5 & $1.07^{\star \star \star}$ & 1.064 to 1.083 \\
\hline Cellulitis & 13284 & 21.5 & $1.05^{\star \star \star}$ & 1.035 to 1.063 \\
\hline Convulsions and epilepsy & 3829 & 5.1 & 1.01 & 0.9905 to 1.023 \\
\hline $\begin{array}{l}\text { Dehydration and Gastro } \\
\text { Intestinal Infection }\end{array}$ & $-4,405$ & -44.9 & $0.94^{\star \star \star}$ & 0.913 to 0.967 \\
\hline Dental & 393 & 3.7 & 1.00 & 0.963 to 1.036 \\
\hline Ear Nose \& Throat infections & 250 & 5.5 & 1.00 & 0.973 to 1.029 \\
\hline Gangrene & -538 & -22.1 & 0.98 & 0.955 to 1.010 \\
\hline Perforated ulcer & $-2,280$ & -38.2 & $0.93^{\star \star \star}$ & 0.898 to 0.967 \\
\hline Pelvic Inflammatory Disease & -314 & -22.5 & 0.96 & 0.893 to 1.038 \\
\hline \multicolumn{5}{|l|}{ Chronic } \\
\hline Total & $-7,442$ & -10.7 & $0.97^{\star * *}$ & 0.969 to 0.979 \\
\hline COPD & 18107 & 1.1 & $1.16^{\star \star \star}$ & 1.157 to 1.171 \\
\hline Congestive Heart Failure & $-1,201$ & -11.4 & $0.97^{\star \star *}$ & 0.961 to 0.980 \\
\hline Diabetic complications & $-11,444$ & -34.1 & $0.91^{\star \star \star}$ & 0.902 to 0.924 \\
\hline Angina & $-8,163$ & -43.8 & $0.90^{\star * *}$ & 0.885 to 0.9195 \\
\hline Asthma & 2877 & 17.6 & $1.03^{\star \star}$ & 1.007 to 1.063 \\
\hline Hypertension & 774 & 3.0 & 1.01 & 0.967 to 1.047 \\
\hline Iron deficiency anaemia & 3916 & 40.5 & $1.05^{\star \star \star}$ & 1.026 to 1.083 \\
\hline Nutritional deficiencies & 174 & 633.7 & 1.08 & 0.838 to 1.380 \\
\hline $\begin{array}{l}\text { ACSC contribution to public } \\
\text { bed days }\end{array}$ & 111726 & 18.2 & $1.03^{\star * *}$ & 1.033 to 1.034 \\
\hline
\end{tabular}

${ }^{*} \mathrm{p}<0.1 ;{ }^{* *} \mathrm{P}<0.05 ;{ }^{* * *} \mathrm{p}<0.01$

ACSC, ambulatory care sensitive condition; COPD, chronic obstructive pulmonary disease.

pulmonary disease (COPD) and pyelonephritis. Influenza and pneumonia accounted for $39.0 \%$ of total ACSC bed days $(n=339613)$, with the proportion of ACSC bed days increasing with increasing age across the three age cohorts examined (table 1; figure 1). The bed day rate increased by $8.2 \%$ (IRR 1.02; $\mathrm{p}<0.01$ ) from 2011 to 2016 (table 2). COPD accounted for almost half of chronic ACSC bed days in 2016 and $14.5 \%$ of total ACSC bed days ( $\mathrm{n}=126336$ bed days; $3831 / 100$ 000). The COPD bed day rate increased (2011-2016) by $1.1 \%$ (IRR:1.16; p<0.01) on a background of a $10.7 \%$ reduction in the chronic ACSC bed day rate over the 5-year period examined.

Pyelonephritis represented almost half (51.2\%; $\mathrm{n}=120285$ bed days; $3681 / 100000)$ of acute ACSC bed days in 2016 and $13.8 \%$ of total ACSC bed days. The bed day rate for pyelonephritis increased by $46.5 \%$ over the 5 years examined.

\section{Examination by age cohort}

When age-specific bed day rates were examined significant variation becomes apparent (figure 2). ACSC conditions were concentrated in the older population, with adults 65 and older representing $69.1 \%$ of ACSC bed days $(n=602392$ bed days; $94483 / 100000)$ in 2016. The impact of ACSCs on total bed days also increased with age, with ACSC bed days representing a quarter of total bed days in this age cohort. Vaccine preventable conditions represented $41.3 \%$ of ACSC bed days among this cohort of which 99\% ( $\mathrm{n}=248524$ bed days; 41 933/100 000) were due to influenza and pneumonia. COPD was the most significant chronic ACSC among this age 


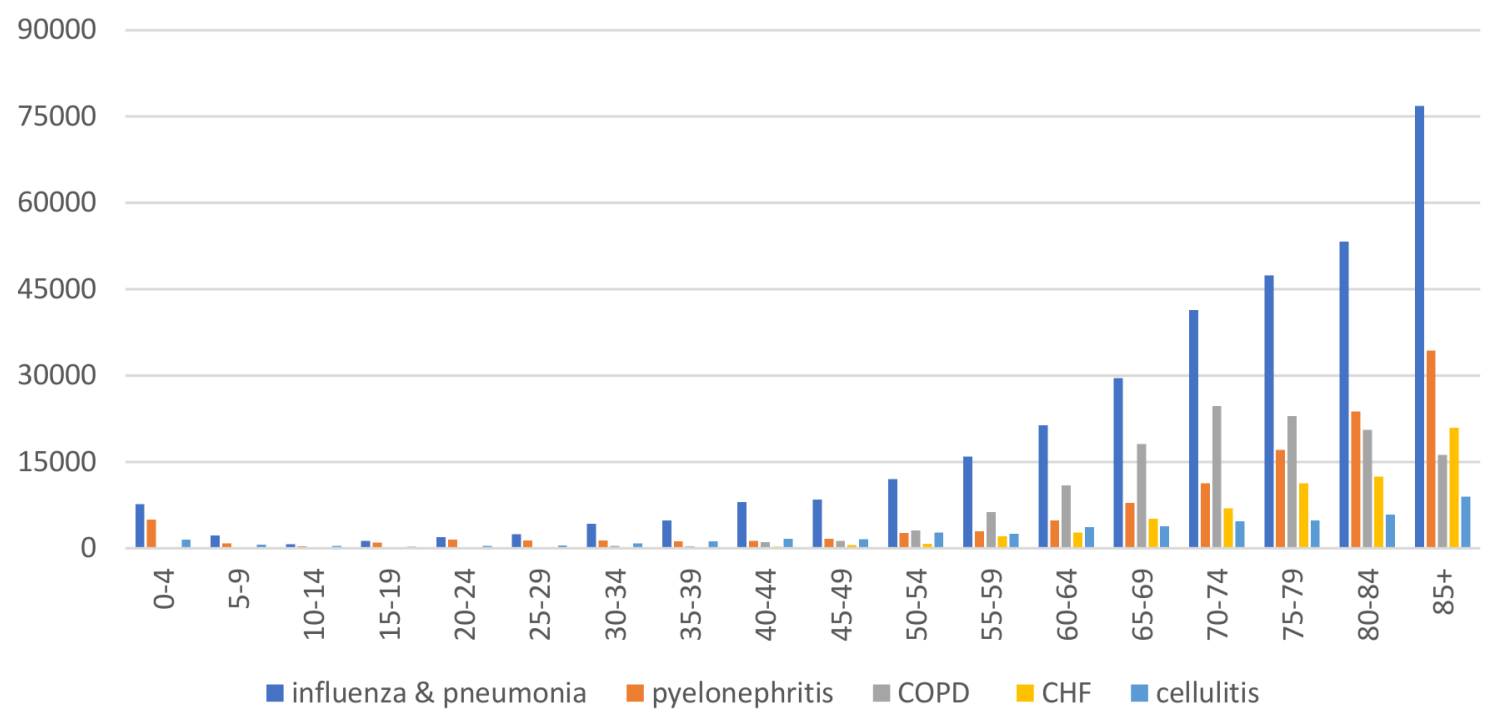

Figure 2 Bed day rate by 5-year age bands for top three ACSCs among total population. ACSC, ambulatory care sensitive condition; COPD, chronic obstructive pulmonary disease.

cohort accounting for more than 100000 bed days (16 $749 / 100000)$. In 2016, pyelonephritis was the most significant acute ACSC in this cohort with 94338 bed days (16 $145 / 100000)$. The bed day rate due to pyelonephritis increased by $46.5 \%$ over the 5 years examined (IRR 1.07 ; $\mathrm{p}<0.01$ ) (table 2).

In the child cohort ( $0-14$ years), $13.8 \%$ of total acute hospital bed days were attributable to ACSCs, representing 46802 bed days in 2016 (table 2). Acute ACSCs represented $63.4 \%$ ( $\mathrm{n}=29822$ bed days; 2089/100 000), with ENT infections the leading acute condition, representing 19.4\% ( $\mathrm{n}=9090$ bed days; 881/100 000) of ACSC bed days in 2016. Vaccine preventable ACSCs represented almost a quarter $(24.1 \%)$ of ACSC bed days, with influenza and pneumonia being responsible for the majority of these.

Within the adult cohort (15-64 years), $11.0 \%$ $(\mathrm{n}=222936$ bed days; $7113 / 100000)$ of total bed days were attributable to ACSCs (table 1). The most significant ACSC condition among this age cohort was the vaccine preventable category influenza and pneumonia. Acute and chronic ACSCs contributed similar proportions to bed days at approximately one-third each.

\section{DISCUSSION}

The 19 ACSCs identified for inclusion in this analysis accounted for almost $20 \%$ of the total publicly funded acute hospital bed days in 2016 or 871328 bed days. When examined in relation to age specific cohorts, adults 65 years and over represented $69.1 \%$ of all ACSC bed days. Just over half of ACSC bed days in 2016 were among respiratory conditions; influenza and pneumonia and COPD. Influenza and pneumonia was the single most important contributor to ACSC bed days across all age cohorts, increasing by $8.2 \%$ over the 5 years examined.
The majority of these bed days $(73.2 \%$; $=248524$ bed days) were among adults 65 years and over. COPD represented $14.5 \% \quad(n=126336)$ of ACSC bed days in 2016, with $81.3 \%$ of these in adults 65 years and over. Pyelonephritis was the next biggest contributor to bed days, representing $13.8 \%$ of ACSC bed days. Again, the relative contribution to bed days increased with age, with adults 65 years and over representing $78.4 \%$. Over the 5 -year period examined bed days due to pyelonephritis increased significantly $(46.5 \%)$.

Evidence-based models of care for influenza and pneumonia include integrated care programmes which include prevention. Seasonal influenza and pneumococcal vaccination remain the mainstay of preventing mortality and morbidity associated with influenza and pneumonia in Ireland and internationally. Seasonal influenza vaccination is recommended for disease specific risk groups including those with COPD, adults 65 years and over and healthcare workers (HCWs). Pneumococcal vaccination is recommended for those 65 and over and those with COPD. While the absolute impact of seasonal influenza and pneumococcal vaccination remains difficult to quantify, recent studies confirm their effectiveness at reducing the risk of pneumococcal pneumonia as well as hospitalisation from respiratory illness among adults 65 and over. ${ }^{1112}$ Despite this, uptake of seasonal influenza vaccine in Ireland consistently lags behind our closest neighbour the UK, while rates of uptake of pneumococcal vaccination are not routinely collected. In Ireland, uptake of seasonal influenza vaccine among adults 65 and over was $56.9 \%$ for the $2012 / 2013$ season, with uptake among HCWs at just $17.6 \%$. Pneumococcal vaccine uptake was estimated at $36 \%{ }^{13-15}$ Comparatively, in the UK, seasonal influenza vaccination rates consistently approach or exceed $70 \%$ among adults over 65 , with HCW vaccination 
Table 3 Comparative vaccination uptake figures 2012/2013 and 2017/2018

\begin{tabular}{|c|c|c|c|c|c|c|c|}
\hline & \multicolumn{4}{|l|}{$2012 / 2013$} & \multicolumn{3}{|l|}{$2017 / 2018$} \\
\hline & $\begin{array}{l}\text { Seasonal } \\
\text { Influenza } \\
\text { vaccine } \\
\text { uptake } 65\end{array}$ & $\begin{array}{l}\text { Seasonal } \\
\text { influenza } \\
\text { vaccine } \\
\text { uptake HCW }\end{array}$ & $\begin{array}{l}\text { Invasive } \\
\text { Pneumococcal } \\
\text { Vaccine uptake } \\
65\end{array}$ & $\begin{array}{l}\text { Pneumonia (\% ACSC } \\
\text { admissions) }\end{array}$ & $\begin{array}{l}\text { Seasonal } \\
\text { influenza } \\
\text { vaccine } \\
\text { uptake } 65\end{array}$ & $\begin{array}{l}\text { Seasonal } \\
\text { influenza } \\
\text { vaccine } \\
\text { uptake HCW }\end{array}$ & $\begin{array}{l}\text { IPV } \\
\text { uptake } 65\end{array}$ \\
\hline Ireland & $56.9 \%$ & $17.6 \%$ & $38.0 \%$ & $29.0 \%-35.0 \%$ & $68.0 \%$ & $44.8 \%$ & $38.0 \%$ \\
\hline UK & $74.0 \%$ & $45.6 \%$ & $69.1 \%$ & $15.0 \%$ & $70.5 \%$ & $68.7 \%$ & $69.5 \%$ \\
\hline
\end{tabular}

ACSC, ambulatory care sensitive condition; HCW, healthcare worker.

rates consistently above Irish estimates (table 3). ${ }^{16} 17$ For the $2012 / 2013$ season, for which comparative data is available, pneumonia represented approximately $10 \%$ of ACSC admissions in the UK compared with approximately $30 \%$ in the Irish setting. ${ }^{1}$ These estimates support the continued emphasis on seasonal influenza and pneumococcal vaccination for HCWs and adults 65 and over, as well as the regular monitoring of pneumococcal vaccination uptake rates in Ireland.

Ireland consistently has one of the highest admission and re-admission rates for COPD in the Organization for Economic Co-operation and Development (OECD). ${ }^{18} 19$ COPD is also one of the most resource intensive Dagnosis Related Groups in acute hospitals in Ireland. ${ }^{6}$ Mortality rates in Ireland due to chronic lower respiratory diseases are $42 \%$ higher than the EU average. ${ }^{6}$ Pulmonary rehabilitation is one of the most cost-effective treatments available. $^{20}$ At a cost of 2,000-8,000 per Quality Adjusted Life Year, it is known to be effective at improving quality of life and reducing hospital admissions. Despite being recognised as the standard of care, this programme is not routinely available in Ireland. ${ }^{21}$ While COPD patients are identified as a risk group for both influenza and pneumococcal vaccination in Ireland, vaccination uptake among this group is not routinely measured or reported. ${ }^{18}$ This paper provides evidence to support implementation of an integrated care programme for COPD focusing on primary care investment to reduce pressure on acute hospitals and improve the quality of care for patients delivered closer to home.

The impact and increase observed for pyelonephritis is surprising, though a similar trend has been observed in the UK. ${ }^{10}$ Further exploration of this phenomenon is necessary in order to ascertain patient profile and appropriateness of admissions. Available evidence demonstrates that with appropriate primary care support in the form of diagnostics, treatment guidelines and preventive approaches, admissions can be reduced and care provided closer to home. $^{22}$

\section{CONCLUSION}

ACSCs are a high-level indicator of potentially avoidable hospitalisation with admissions known to be correlated with primary care provision as well as with deprivation. ${ }^{1810}$ The impact of ACSCs on acute hospital capacity is best measured using bed day rates. This analysis can be used to identify conditions that would benefit from investment in primary and community care. Identifying specific conditions by their impact on acute hospital capacity supports closer examination of integrated models of care for these conditions. $^{720}$ This analysis not only supports the left shift to provision of care within the community called for in Slaintecare, but enables prioritisation of resources to primary care. ${ }^{6}$

ACSCs were responsible for almost one-fifth of all acute hospital bed day usage in 2016 in Ireland. While the proportion of these admissions that represent truly avoidable admissions will require further exploration, an examination of the impact of these conditions in terms of bed days make a compelling argument for prioritising the development of integrated models of care with primary and community services, enabling the 'left shift' of care closer to home envisioned within government policy. ${ }^{6} 23$

Collaborators Planning for Health Group, Department of Public Health, HSE West.

Contributors BS: consultant in Public Health Medicine developed the study protocol and provided ongoing support to data analysis and interpreted. GM: specialist registrar in Public Health Medicine, performed data extraction and analysis. Both authors have given final approval for publication and are accountable for all aspects of the work. This work was conducted within the work programme of the Planning for Health Group.

Funding The authors have not declared a specific grant for this research from any funding agency in the public, commercial or not-for-profit sectors.

Competing interests None declared.

Patient consent for publication Not required.

Ethics approval As the analysis represents a secondary analysis of an anonymised data set, ethical approval was not required.

Provenance and peer review Not commissioned; externally peer reviewed.

Data availability statement Data are available upon reasonable request.

Open access This is an open access article distributed in accordance with the Creative Commons Attribution Non Commercial (CC BY-NC 4.0) license, which permits others to distribute, remix, adapt, build upon this work non-commercially, and license their derivative works on different terms, provided the original work is properly cited, appropriate credit is given, any changes made indicated, and the use is non-commercial. See: http://creativecommons.org/licenses/by-nc/4.0/.

\section{REFERENCES}

1 Billings J, Zeitel L, Lukomnik J, et al. Impact of socioeconomic status on hospital use in New York City. Health Aff (Millwood) 1993;12:162-73.

2 Purdy S, Griffin T, Salisbury C, et al. Ambulatory care sensitive conditions: terminology and disease coding need to be more specific to aid policy makers and clinicians. Public Health 2009;123:169-73. 
3 Page A, Ambrose S, Glover J, et al. Atlas of avoidable hospitalisations in Australia: ambulatory care-sensitive conditiobns. Australian Institute of Health and Welfare and the University of Adelaide, 2007.

4 Department of Health. Health service capacity review 2018: review of health demand and capacity requirements in Ireland to 2031-findings and recommendations. Dublin, Ireland: Department of Health, 2018.

5 Smyth BM, Donohue P, Kavanagh F, et al. Planning for health: trends and priorities to inform health service planning 2017. Dublin, Ireland: Health Service Executive, 2016.

6 The Houses of the Oireachtas DoH. Oireachtas Committee on the future of healthcare. Slaintecare report. Dublin: Oireachtas, $\mathrm{DOH}$, 2017.

7 Tian Y, Dixon A, Gao H. Emergency hospital admissions for ambulatory care-sensitive conditions: identifying the potential for reductions. The King's Fund, 2012.

8 Sheridan A, Howell F, Bedford D. Hospitalisations and costs relating to ambulatory care sensitive conditions in Ireland. Ir J Med Sci 2012;181:527-33.

9 Lynch B, Fitzgerald AP, Corcoran P, et al. Drivers of potentially avoidable emergency admissions in Ireland: an ecological analysis. BMJ Qual Saf 2019;28.

10 Blunt I. Focus on preventable admissions, trends in emergency admissions for ambulatory care sensitive conditions 2001 to 2013. UK: The Health Foundation \& Nuffield Trust, 2013.

11 Trucchi C, Paganino C, Orsi A, et al. Influenza vaccination in the elderly: why are the overall benefits still hotly debated? J Prev Med Hyg 2015;56:E37-43.

12 Falkenhorst G, Remschmidt C, Harder T, et al. Effectiveness of the 23-valent pneumococcal polysaccharide vaccine (PPV23) against pneumococcal disease in the elderly: systematic review and metaanalysis. PLoS One 2017;12:e0169368.

13 HSE Health Protection Surveillance Centre. Uptake of seasonal influenza vaccine in acute hospitals and long term care facilities in Ireland in 2017-2018. Dublin: HSE HPSC, 2018.
14 Mereckiene J, Domegan L, O'Lorcain P. Seasonal influenza vaccination trends for at risk groups, the importance of data collection and reporting. fighting the flu together. Sligo, Ireland, 2018

15 Giese C, Mereckiene J, Danis K, et al. Low vaccination coverage for seasonal influenza and pneumococcal disease among adults at-risk and health care workers in Ireland, 2013: the key role of GPs in recommending vaccination. Vaccine 2016;34:3657-62.

16 Public Health England. Seasonal flu vaccine uptake (GP) 2012/13Data on GP registered patients, 2013. Available: https://assets. publishing.service.gov.uk/government/uploads/system/uploads/ attachment_data/file/676221/SeasonalFluData_GPs_Jan13_acc. pdf

17 Public Health England. Seasonal influenza vaccine uptake amongst frontline healthcare workers (HCWs) in England. Winter season 2012/13, 2013. Available: https://assets.publishing.service.gov.uk/ government/uploads/system/uploads/attachment_data/file/245605/ Seasonal Influenza Vaccine Uptake HCWs 2012 13.pdf

18 Crinion S, Cotter O, Kennedy B, et al. Copd exacerbations-a comparison of Irish data with European data from the ERC COPD audit. Ir Med J 2013;106:268:270-2.

19 OECD. Health at a glance 2017: OECD indicators. Paris: OECD, 2017.

20 Vogiatzis I, Rochester CL, Spruit MA, et al. Increasing implementation and delivery of pulmonary rehabilitation: key messages from the new ATS/ERS policy statement. Eur Respir J 2016;47:1336-41.

21 Petty-Saphon N, O'Reilly O, O'Connor M. National needs assessment for pulmonary rehabilitation services-report to the integrated care programme for the prevention and management of chronic disease 2016 Clinical Strategies and Programmes; 2016.

22 Rowe TA, Juthani-Mehta M. Urinary tract infection in older adults. Aging health 2013;9:519-28.

23 Health Service Executive. National service plan 2018. Dublin HSE; 2017. 